\title{
Seguindo em busca do "Esquivo Desenvolvimento Regional": considerações sobre avanços e desafios da PNDR no sul do Brasil ${ }^{1}$
}

\author{
Tanise Dias Freitas ${ }^{2}$ \\ Anelise Graciele Rambo ${ }^{3}$
}

\begin{abstract}
Resumo: Neste trabalho buscou-se tecer considerações sobre a Política Nacional de Desenvolvimento Regional (PNDR) analisando seus avanços e desafios à luz das dinâmicas territoriais promovidas pelo Programa de Promoção da Sustentabilidade de Espaços Sub-regionais (Promeso), tendo como caso específico o estudo da Mesorregião Grande Fronteira do Mercosul. O enfoque teórico está subsidiado na ideia de desenvolvimento como satisfação das necessidades humanas fundamentais, e que se fortalece na interação dos processos globais com os comportamentos locais, na interação do pessoal com o social, do planejamento com a autonomia e da sociedade civil com o Estado. No aspecto metodológico foram utilizados dados secundários provenientes de publicações oficiais sobre a PNDR, bem como pesquisa empírica realizada através da técnica de entrevista com os membros do fórum da mesorregião nos três estados do sul do Brasil. Assim, os resultados permitem afirmar que a PNDR avançou ao trazer para a agenda pública regiões e atores que anteriormente não eram foco das políticas de desenvolvimento. Por meio da referida política, atores locais/regionais passaram a discutir suas demandas, necessidades e interesses, valorizando o capital territorial. Verificaram-se avaliações positivas no que se refere à contribuição das políticas para o desenvolvimento, gerando renda, qualidade de vida e maior preocupação com o meio ambiente. Já sobre desafios, evidenciaram-se as ações pontuais dos projetos implementados, de caráter local e não regional, o forte vínculo dos planos aos recursos da política e a necessidade de maior participação dos atores locais e a interação com outras escalas de gestão do desenvolvimento regional.
\end{abstract}

Palavras-chave: Desenvolvimento Regional. Política Pública. PNDR. Região Sul. Dinâmicas Territoriais.

Abstract: In this paper we intend to make considerations about the National Policy of Regional Development (PNDR) analyzing its advances and challenges in light of the territorial dynamics promoted by the Program for the Promotion of Sustainability of Sub-regional Spaces (Promeso), and having as a specific case the study of the Great Frontier Mesoregion of Mercosur. The theoretical approach is subsidized in the idea of development as satisfaction of fundamental human needs, and that is strengthened in the interaction of global processes with local behaviors, in the interaction of the personnel with the social, of the planning with the autonomy and of the civil society with the State. On the methodological side, secondary data were used from official publications on $P N D R$, as well as empirical research conducted through the interview technique with the eight members of the forum of the mesoregion in the three southern states of Brazil. Thus, the results allow us to affirm that the NDRP has advanced by bringing to the public agenda regions and actors that were previously not the focus of development policies. Through this policy, local / regional actors began to discuss their demands, needs and interests, valuing the territorial capital. There have been positive assessments of the contribution of development policies, generating income, quality of life and greater concern for the environment. Regarding challenges, the specific actions of the implemented projects, of local and non-regional character, the strong

\footnotetext{
${ }^{1}$ Este trabalho é resultado do Projeto de Pesquisa da Chamada MCTI/CNPq/MEC/CAPES № 43/2013.

2 Pesquisadora DOCFIX-FAPERGS no Programa de Pós-Graduação em Desenvolvimento Regional. Doutora em Sociologia (UFRGS). tanise1208@yahoo.com.br

${ }^{3}$ Professora do Departamento Interdisciplinar do Campus Litoral Norte (UFRGS). Doutora em Desenvolvimento Rural.ane_rambo@yahoo.com.br
} 
linkage of the plans to the resources of the policy and the need for greater participation of local actors and interaction with other regional development management scales.

Keywords: Regional development. Public policy. PNDR. South Region. Territorial Dynamics.

\section{Introdução}

Ao longo das últimas décadas observa-se uma mudança contínua nas concepções quanto à dinâmica e ao significado do que seria "desenvolvimento". Este termo que se dissemina principalmente após a Segunda Guerra Mundial, já representou riqueza, evolução, progresso, crescimento, industrialização, modernização, incremento dos índices socioeconômicos e ambientais, bem como, liberdade. Quanto à sua dinâmica, já se considerou o desenvolvimento resultante da atuação do Estado, seja keynesiano ou desenvolvimentista, ou então, do livre jogo das forças do mercado a partir de uma ótica neoliberal.

As primeiras abordagens que dão ênfase a processos localizados de desenvolvimento têm início ainda no século XIX, com as teorias clássicas da localização, e já no final do século XX com autores como Perroux (Pólos de Crescimento), Myrdal (Causação Circular e Cumulativa), Hirschman (Encadeamentos para frente e para trás) e North (Teoria da Base de Exportação). Essas abordagens pautadas nos fatores de aglomeração orientaram políticas públicas de desenvolvimento regional. As políticas de incentivos fiscais e financeiros, ao buscarem alterar a estrutura de custos das empresas em regiões determinadas, apoiam-se nesse tipo de argumentação, no intuito de redefinir a decisão "locacional" das firmas (MONASTERIO, CAVALCANTE, 2011).

Entretanto, observa-se que tais políticas, alcançaram poucos resultados no que se refere à promoção do desenvolvimento e redução das desigualdades, principalmente entre as diferentes regiões. Assim, a partir de 1980, ganham destaque as concepções que deixam de compreender o desenvolvimento como um processo top-down, passando a considerá-lo numa perspectiva botton-up, entendendo as regiões como promotoras do seu desenvolvimento (FERNÁNDEZ, AMIN, VIGIL, 2008). 
No Brasil, seguindo uma tendência mundial, inclusive de instituições internacionais de promoção e financiamento do desenvolvimento, ganhou espaço a ideia sobre a necessidade de criar mecanismos que possibilitassem uma participação mais efetiva e direta da comunidade na formulação, implementação e acompanhamento das políticas públicas, dando maior autonomia e protagonismo a esta comunidade no processo de desenvolvimento. Essa participação da sociedade é fundamental para a promoção de um desenvolvimento conectado às realidades locais/regionais, o que assume importância no Brasil, devido a sua extensão e diversidade territorial.

Acredita-se que as políticas de desenvolvimento são mais eficazes se concebidas e implementadas com a participação dos atores locais e não por uma administração central (BARQUERO, 2001). As próprias políticas do Banco Mundial, especialmente a partir dos anos 2000, apontam para a "endogeneidade" dos processos de desenvolvimento, o que possibilitaria a criação de coalizões e sinergias, com uma dinâmica potencialmente autossustentável. No entanto, críticas vêm sendo tecidas a estas contribuições por subestimarem o papel do Estado e minimizarem a força do processo de corporativização dos territórios, decorrentes do aumento da influência dos grandes grupos multinacionais na definição de investimentos públicos (FERNÁNDEZ, AMIN, VIGIL, 2008).

Com base nestas perspectivas sobre o desenvolvimento e suas transformações conceituais, o presente trabalho tem como objetivo entender a Política Nacional de Desenvolvimento Regional (PNDR), criada no Brasil nos anos 2000 e que tem como escopo o fortalecimento das dinâmicas e dos atores locais como promotores do desenvolvimento. $\mathrm{O}$ foco deste estudo é entender quais os alcances e limites da PNDR a partir do estudo de um de seus programas principais, a saber, o Programa de Promoção da Sustentabilidade de Espaços Sub-regionais (Promeso), o qual foi implementado na Mesorregião Diferenciada da Grande Fronteira do Mercosul (GFM) que abrange áreas territoriais do Paraná, de Santa Catarina e do Rio Grande do Sul. A proposta deste trabalho é entender como este programa possibilitou, em maior ou menor intensidade, o desenvolvimento destas regiões.

Para tanto, foram analisados diferentes documentos oficiais publicados pelo Ministério da Integração Nacional, Instituto de Pesquisa Econômica Aplicada, bem como outras referências bibliográficas que estudaram a PNDR no Brasil. De posse desses materiais, 
foi realizada pesquisa empírica através da técnica de entrevista semiestruturada com membros do Fórum GFM nos três estados a fim de mensurar qualitativamente a importância da PNDR e seus instrumentos para o desenvolvimento regional.

Assim, o presente trabalho estrutura-se com esta introdução, seguida da seção 2 que descreve a evolução das Políticas Públicas de Desenvolvimento Regional no Brasil, relacionando-as com as perspectivas teóricas vigentes. Disto, parte-se para apresentação da PNDR, suas tipologias e instrumentos, dando destaque à incidência desta política na região sul do Brasil. Na terceira seção focaliza-se no estudo da Mesorregião da Grande Fronteira do Mercosul (estudo de caso) a fim de compreender os limites e alcances da PNDR como uma política de superação das disparidades regionais.

\section{Desenvolvimento regional e políticas públicas no Brasil}

As desigualdades econômicas e sociais formaram-se no Brasil desde o processo de colonização que privilegiou a região litorânea (FURTADO, 2003). Posteriormente, a geração de riquezas passou a se concentrar nas regiões Sudeste e Sul, relegando às demais regiões condições menos favoráveis. Segundo dados do IPEA (2012), o crescimento econômico brasileiro até meados da década de 1950 aconteceu provocando desigualdades regionais bastante profundas, tendo em vista que as atividades econômicas se concentravam especialmente nas regiões Sul e Sudeste, e nesta, principalmente em São Paulo.

Dentre os anos de 1940 e 1970 ocorreram no Brasil diversas tentativas de promover o desenvolvimento, tais como a criação da Superintendência do Plano de Valorização Econômica da Amazônia (SPVEA), que delimitou uma região, a Amazônia Legal, a Superintendência do Plano de Valorização Econômica da Região da Fronteira Sudoeste; criação do Departamento Nacional de Obras Contra as Secas (DNOCS) no nordeste, o Instituto do Açúcar e do Álcool (IAA), que estabelecia cotas de produção para cada estado; o Banco do Nordeste do Brasil (BNB). Podemos citar ainda a criação do Banco Nacional de Desenvolvimento Econômico (BNDE), cujo objetivo era ser o órgão formulador e executor da política nacional de desenvolvimento econômico e posteriormente veio a se chamar Banco Nacional de Desenvolvimento Social e Econômico (BNDES) (MENDES, MATTEO, 2011). 
Em 1959 criou-se a Superintendência para o Desenvolvimento do Nordeste (Sudene) como "a primeira efetiva tentativa de, a partir de um plano de desenvolvimento, executar uma política regional" (MENDES; MATTEO, 2011, p.274). Também foram constituídas a Superintendência de Desenvolvimento da Amazônia (SUDAM), o Banco da Amazônia (BASA) e a Superintendência da Zona Franca de Manaus (Suframa); a Superintendência de Desenvolvimento do Centro-Oeste (SUDECO) e a Superintendência de Desenvolvimento da Região Sul (SUDESUL). O objetivo geral destas superintendências era reduzir os desequilíbrios inter e intrarregionais e amenizar as desigualdades existentes nas diferentes regiões do país e para atender mais adequadamente às especificidades regionais (IPEA, 2012).

As crises inflacionárias, iniciadas no final da década de 1970 e que perduraram nos anos 1980, prejudicaram e estagnaram a continuidade das ações voltadas ao planejamento, as quais estiveram focadas nestes anos no combate à inflação. O mesmo ocorreu na década de 1990, com o desenvolvimento pautado nas deliberações do Consenso de Washington, reduzindo as atribuições do Estado para regular e suprir as falhas de mercado. As instâncias regionais e estaduais de planejamento ficaram praticamente desmobilizadas nestas épocas (MENDES; MATTEO, 2011).

Conforme Dupas (2006), o discurso neoliberal enfraqueceu as economias nacionais. O vácuo teórico e a dificuldade de gestão estatal, abriu espaço para os defensores do Estado mínimo. Porém, a consequência desse processo foi uma sucessão de crises que afetaram particularmente a América Latina e a maioria dos países da periferia, provocando um aumento significativo da exclusão social em boa parte do mundo. Acarretou a acumulação de capital, em detrimento do bem-estar social, portanto, tais políticas, mostraram poucos resultados no que se refere à promoção do desenvolvimento e redução das desigualdades.

A partir dos anos 2000, e cumprindo as determinações da Constituição Federal de 1988, tornou-se obrigatória a elaboração de Planos Plurianuais para os governos, destacando preocupações com o planejamento e o desenvolvimento regional que voltaram a ocupar os debates nos espaços públicos. Assim, pode-se dizer que o marco na retomada das políticas de desenvolvimento regional deu-se com a criação da PNDR, no ano 2003. Esta política, embora com discretos avanços quanto à diminuição das desigualdades regionais e 
resultados práticos pouco expressivos, mantém-se na agenda governamental até a atualidade e representa avanços no que se refere ao planejamento do desenvolvimento regional no Brasil, como será apresentado a seguir.

Já a abordagem (prático/instrumentalista) de território passou a fazer parte do vocabulário das políticas públicas, em 2003. Neste ano tem-se a criação da Política Nacional de Ordenamento Territorial (Pnot), com objetivo de dirimir conflitos de interesse e imprimir uma trajetória convergente para o uso harmonioso do território em consonância com os objetivos do desenvolvimento sustentável que o país almeja (GALVÃO, 2005). Porém, maiores avanços na perspectiva territorial foram observados a partir de outra ação, qual seja, a criação da Secretaria do Desenvolvimento Territorial (SDT), ligada ao Ministério do Desenvolvimento Agrário (MDA). Neste âmbito é criado no mesmo ano, o Programa Desenvolvimento Sustentável de Territórios Rurais (Pronat) seguido do Programa Territórios da Cidadania (PTC), criado em 2008.

Ainda em 2006, foi realizado o "Estudo para Subsidiar a Abordagem da Dimensão Territorial do Desenvolvimento Nacional no Plano Plurianual PPA 2008-2011 e no Planejamento Governamental de Longo Prazo" ${ }^{4}$ com objetivo de prover subsídios ao processo de elaboração do PPA 2008-2011 e subsequentes, contribuindo para a estruturação do planejamento territorial no Brasil. O estudo pretendia gerar contribuições para o aperfeiçoamento do planejamento no país considerando a dimensão territorial do desenvolvimento consubstanciada nos Planos Plurianuais (BRASIL, 2006).

Essa perspectiva territorial presente nas ações do Estado brasileiro reflete uma tendência internacional que atribui importância e protagonismo às escalas locais e às dinâmicas territoriais. Portanto, cada vez mais múltiplos atores e múltiplas escalas são considerados nos processos de desenvolvimento, sejam eles atores pertencentes ao Estado, ao mercado, e a sociedade civil de escalas locais, regionais, nacionais e mesmo supranacionais (RAFFESTIN, 1993, RÜCKERT, 2005).

Boisier (2000) destaca que na medida em que se reconhece no desenvolvimento um sistema complexo, multidimensional, construtivista, qualitativo em sua essência e intangível por consequência, o paradigma que vem dominando o desenvolvimento científico da

\footnotetext{
${ }^{4}$ Contrato celebrado entre Ministério do Planejamento, Orçamento e Gestão (MP) e o Centro de Gestão e Estudos Estratégicos (CGEE), publicado no dia 4 de setembro de 2006 no Diário Oficial da União no 170.
} 
modernidade deixa de ser útil para entender o desenvolvimento por seu caráter reducionista, mecanicista e linear. O autor ressalta que um desenvolvimento que não promove e fortalece confianças, reconhecimentos e sentidos coletivos, carece em curto prazo de uma sociedade que o fomente.

Dessa forma, a viabilidade e êxito de um programa de desenvolvimento dependerão do grau em que as pessoas percebem esse programa como um cenário em que sua subjetividade coletiva é reconhecida e fortalecida. O desenvolvimento sustenta-se então na satisfação das necessidades humanas fundamentais, na geração de níveis crescentes de autoconfiança, na articulação orgânica dos seres humanos com a natureza e a tecnologia. Esse processo acaba sendo fortalecido na interação dos comportamentos globais com os locais, na interação do indivíduo com a coletividade, do planejamento com a autonomia e da sociedade civil com o Estado.

Isso remete a construção de um projeto político regional coletivo, o qual, para Boisier (1995), deve articular seis elementos: atores, instituições, recursos (materiais, humanos, psicossociais e de conhecimento), procedimentos de gestão, cultura (de autorereferência, solidariedade e cooperação) e o entorno ${ }^{5}$ (o mercado, o Estado e as relações internacionais). Além desses elementos, o autor destaca a necessidade de uma articulação densa e inteligente para promoção do desenvolvimento local/regional. Do contrário, não se terá senão uma caixa preta, cujo conteúdo e funcionamento se desconhecem.

Ainda nesse sentido, Brandão (2008) descreve que as políticas de desenvolvimento precisam agir sobre a totalidade do tecido socioprodutivo, pensar o conjunto territorial como um todo sistêmico, promovendo ações concertadas naquele espaço geográfico, buscando reduzir disparidades inter-regionais, combatendo o fosso entre as regiões e ampliando a autodeterminação daquela comunidade. A partir deste breve resgate sobre o planejamento do desenvolvimento regional no Brasil, e algumas considerações sobre concepções de desenvolvimento, passa-se para a caracterização da PNDR, destacando elementos que possibilitem identificar sua atuação na região sul do Brasil.

\footnotetext{
${ }^{5}$ Segundo Brandão (2003), qualquer diagnóstico local, regional ou nacional deveria explicitar os conflitos e compromissos postos; posicionar a região ou a cidade no contexto: mesorregional, estadual, nacional etc.; identificar seus nexos de complementaridade econômica; estudar sua inserção frente aos ritmos diferenciados dos processos econômicos dos diversos territórios com os quais se relaciona. Não se pode negligenciar a natureza das hierarquias imputadas.
} 


\section{A Política Nacional de Desenvolvimento Regional (PNDR)}

A Política Nacional de Desenvolvimento Regional, no Brasil, teve sua institucionalização pelo Decreto no 6.047 de 22 de fevereiro de 2007, embora criada ainda em 2003, sendo executada pela Secretaria de Programas Regionais (SPR) do Ministério da Integração Nacional (MI). Segundo o MI, o objetivo principal da PNDR consiste em reduzir as desigualdades regionais e ativar os potenciais de desenvolvimento das regiões no País. Ainda, a PNDR tem os seguintes objetivos específicos (BRASIL, 2015):

a) Dotar as regiões das condições necessárias - infraestrutura, crédito, tecnologia etc. - ao aproveitamento de oportunidades econômico-produtivas promissoras para seu desenvolvimento;

b) Promover a inserção social produtiva da população, a capacitação dos recursos humanos e a melhoria da qualidade da vida em todas as regiões;

c) Fortalecer as organizações socioprodutivas regionais, com a ampliação da participação social e estímulo a práticas políticas de construção de planos e programas sub-regionais de desenvolvimento;

d) Estimular a exploração das potencialidades sub-regionais que advêm da diversidade socioeconômica, ambiental e cultural do país.

Conforme descrito no Sumário Executivo da PNDR, o foco principal desta política não é essencialmente o combate à pobreza, mas se expressa na coincidência espacial entre pobreza individual e regional. De acordo com o Ministério da Integração, uma das premissas da PNDR no âmbito nacional seria o enfrentamento das desigualdades regionais, uma vez que estas diminuem a coesão e a integração territorial do Brasil. A figura 1 mostra a tipologia criada pela política para identificação das regiões demandantes de estratégias de desenvolvimento regional.

De forma prática a PNDR apresenta uma tipologia para identificar as regiões "alvo" das suas ações. Tal caracterização resulta da combinação de dois indicadores básicos de renda e dinamismo, publicados pelo IBGE: (1) o rendimento médio mensal por habitante e (2) a taxa geométrica de variação dos produtos internos brutos municipais por habitante. 
Estes dois indicadores deram origem a quatro tipologias: microrregiões de alta renda, dinâmicas, estagnadas, e de baixa renda, sendo que apenas as primeiras não são alvo da PNDR. Desse modo, das 557 microrregiões brasileiras, apenas 140 são caracterizadas como alta renda e não fazem parte do escopo da PNDR (BRASIL, 2015).

\section{Figura 1 - Tipologia das Sub-Regionais Brasileiras de acordo com critérios da PNDR}



Fonte: Sumário Executivo da PNDR, 2015, p. 32.

A PNDR pretende focalizar a causa da desigualdade e da pobreza, bolsões de pobreza em meio a contextos ricos e dinâmicos (BRASIL, 2015). Sendo assim, pode ser entendida como uma política de Estado e que se baseia na Teoria do Desenvolvimento Endógeno, a partir da qual devem ser compreendidas as diferenças e particularidades de cada região, potencialidades e limites para então buscar alternativas adequadas às suas realidades. Logo, sobre as regiões prioritárias, atuam três tipos de instrumentos principais: (1) os planos regionais; (2) os fundos de desenvolvimento regional e os (3) programas governamentais, (conforme Quadro 1, a seguir). 


\section{Quadro 1 - Principais instrumentos da PNDR}

\begin{tabular}{|l|}
\hline \multicolumn{1}{|c|}{ Planos Regionais } \\
\hline Planos Macrorregionais de Desenvolvimento (Amazônia Sustentável, Nordeste/Semi Árido e Centro-Oeste); \\
\hline Planos Mesorregionais de Desenvolvimento \\
\hline \multicolumn{1}{c|}{ Fundos de Desenvolvimento Regional } \\
\hline Fundo Nacional de Desenvolvimento Regional \\
\hline Fundos Constitucionais de Financiamento ${ }^{6}$ (FNE, FNO, FCO) \\
\hline Fundos de Desenvolvimento Regional do Nordeste (FDNE) e da Amazônia (FDA) \\
\hline \multicolumn{1}{c|}{ Programas Governamentais } \\
\hline Programa de Gestão da Política de Desenvolvimento Regional e Ordenamento Territorial \\
\hline Programa de Promoção do Desenvolvimento da Faixa de Fronteira (PDFF) \\
\hline Programa de Promoção da Sustentabilidade de Espaços Sub-regionais (Promeso) \\
\hline Programa do Desenvolvimento Integrado e Sustentável do Semi Árido (Conviver) \\
\hline
\end{tabular}

Fonte: Elaboração própria. Adaptado de Brasil, 2015.

Dentro dos diferentes instrumentos da PNDR, podemos destacar os Programas Governamentais. No caso específico de atuação na região sul do Brasil tem-se o Programa de Promoção da Sustentabilidade de Espaços Sub-regionais (Promeso) que engloba as Mesorregiões Diferenciadas da Grande Fronteira do Mercosul, foco de análise deste trabalho e da Metade Sul do Rio Grande do Sul. A subseção que segue apresenta o Promeso na Região Sul.

3.1 PNDR e o Programa de Promoção da Sustentabilidade de Espaços Sub-regionais (Promeso)

O Promeso, inserido no PPA 2000/2003, tem como objetivo aumentar a autonomia e a sustentabilidade de espaços sub-regionais por meio da organização social, do desenvolvimento dos seus potenciais endógenos e do fortalecimento das suas bases produtivas, com vistas à redução das desigualdades inter e intrarregionais (BRASIL. 2009). O

\footnotetext{
${ }^{6}$ A Constituição, em seu artigo 159, criou os Fundos Constitucionais, regulamentados. Estes passaram a destinar $3 \%$ do resultado da arrecadação dos impostos sobre rendimentos e produtos industrializados para financiamento dos setores produtivos das Regiões Norte, Nordeste e Centro-Oeste. Importa destacar que os estados que não possuem seus respectivos fundos tiveram suas ações financiadas por emendas parlamentares e, no caso do Rio Grande do Sul. Assim, a não- implementação do Fundo Nacional de Desenvolvimento Regional pode ser considerada como um dos principais entraves que têm dificultado a efetiva elevação da Política a uma condição de Política de Estado (CARGIN, 2014).
} 
Promeso destaca as mesorregiões diferenciadas da PNDR, que significam espaços contínuos, formados por territórios de uma ou mais Unidades da Federação, podendo ser menores que as Macrorregiões do IBGE.

As Mesorregiões são formadas por municípios que apresentam identidades físicas, econômicas, sociais e culturais e permitem a configuração de um arranjo políticoinstitucional com participação da sociedade civil, num processo de busca de coordenação e efetividade das ações territoriais das políticas públicas de diferentes esferas de poder. Esse arranjo político-institucional tem o papel de definir de forma participativa os objetivos específicos e identificar as potencialidades a serem fortalecidas e as vulnerabilidades a serem mitigadas (BRASIL, 2009). A figura que segue mostra as Mesorregiões diferenciadas do Promeso dando destaque à Grande Fronteira do Mercosul (GFM) e Metade Sul do RS, as quais se sobrepõem aos territórios físicos do Paraná, Santa Catarina e Rio Grande do Sul.

Figura 2 - Mesorregiões diferenciadas do Promeso - PNDR

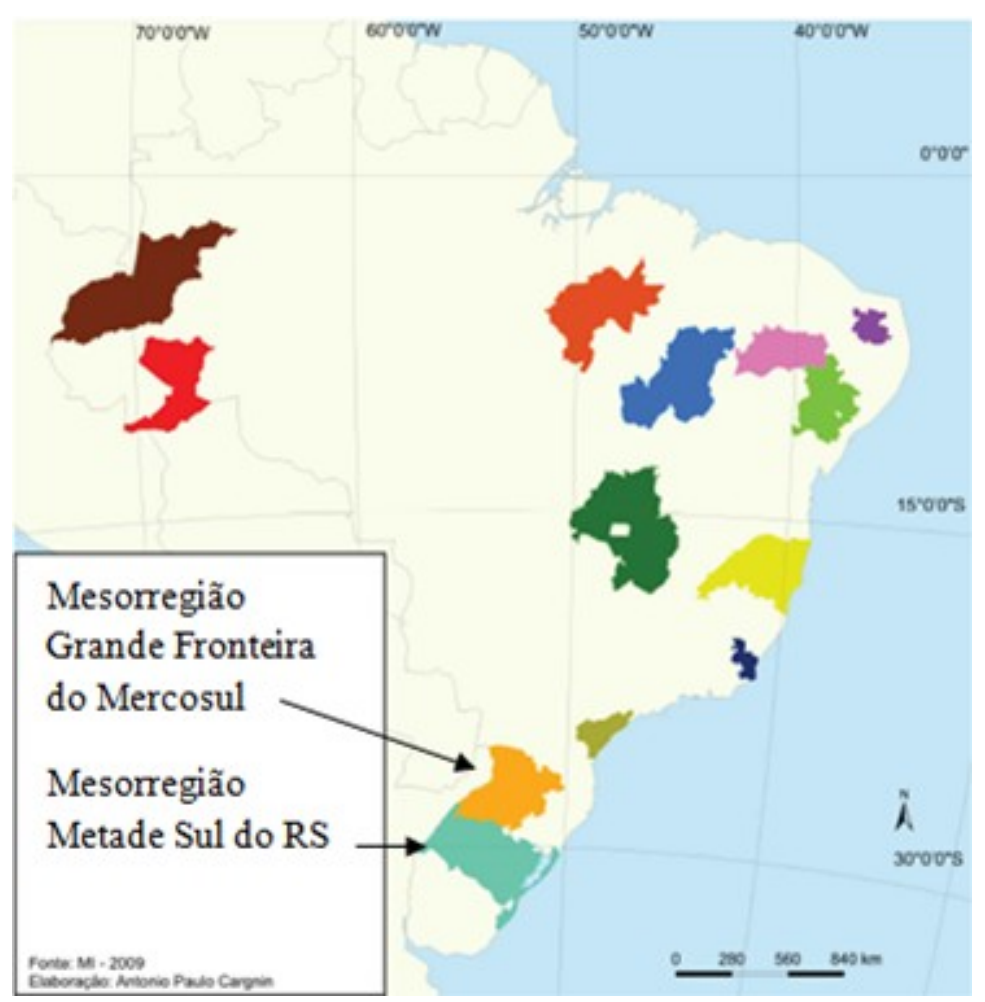

Fonte: Adaptado de Cargnin, 2014

Com base nos objetivos da PNDR, o Promeso busca pela redução das desigualdades regionais a partir de dois eixos principais: (A) a organização social e (B) a ativação 
econômica. O primeiro eixo volta-se ao estímulo e fortalecimento dos fóruns mesorregionais para que sejam canais de participação da sociedade civil na definição de ações a serem contempladas com investimentos públicos. O segundo ocorre por meio do fomento aos Arranjos Produtivos Locais identificados como prioritários nas Mesorregiões Diferenciadas e nas Regiões Integradas de Desenvolvimento (Rides). O quadro que segue traz um comparativo entre as ações realizadas e organizadas no Plano de Desenvolvimento dessas duas mesorregiões.

\section{Quadro 2 - Ações e Executores do Promeso nas Mesorregiões Diferenciadas}

\begin{tabular}{|c|c|c|}
\hline Regiões & Grande Fronteira do Mercosul & Mesorregião da Metade Sul \\
\hline \multirow{8}{*}{ Ações } & $\begin{array}{l}\text { Fortalecimento de agroindústrias } \\
\text { familiares: apoio a aproximadamente } \\
200 \text { agroindústrias }\end{array}$ & Agricultura familiar \\
\hline & $\begin{array}{l}\text { Desenvolvimento do APL de móveis no } \\
\text { oeste catarinense. }\end{array}$ & Florestamento \\
\hline & $\begin{array}{l}\text { Sinalização turística na região das } \\
\text { Missões jesuíticas }\end{array}$ & Sementes agroecológicas na região da Campanha \\
\hline & $\begin{array}{l}\text { Fortalecimento da piscicultura } \\
\text { envolvendo } 200 \text { agricultores familiares }\end{array}$ & $\begin{array}{l}\text { Diversificação da matriz produtiva e estruturação } \\
\text { da cadeia produtiva da fruticultura }\end{array}$ \\
\hline & $\begin{array}{l}\text { Fortalecimento da vitivinicultura com } \\
\text { ações de capacitação de produtores e } \\
\text { técnicos na região atendendo } 250 \\
\text { famílias de agricultores familiares }\end{array}$ & $\begin{array}{l}\text { Projeto de Vitivinicultura que envolve municípios } \\
\text { do centro e oeste da Mesorregião, prevê a } \\
\text { implantação de um centro regional de } \\
\text { vitivinicultura, que deverá ser gerenciado pela } \\
\text { Empresa Brasileira de Pesquisa Agropecuária } \\
\text { (Embrapa). }\end{array}$ \\
\hline & $\begin{array}{l}\text { Lapidação e artesanato mineral para } \\
\text { fomentar o uso de tecnologias } \\
\text { apropriadas envolvendo } 2.200 \\
\text { garimpeiros. }\end{array}$ & $\begin{array}{l}\text { Gemas e joias na região centro e em alguns } \\
\text { municípios do oeste }\end{array}$ \\
\hline & $\begin{array}{l}\text { Apoio ao setor lácteo com ações para } \\
\text { cerca de } 30 \text { associações de produtores } \\
\text { de leite no oeste catarinense }\end{array}$ & $\begin{array}{l}\text { Agroindústria do leite com estruturação da } \\
\text { agroindústria em Santa Vitória do Palmar }\end{array}$ \\
\hline & $\begin{array}{l}\text { Criação, indiretamente, da } \\
\text { Universidade Federal da Fronteira Sul } \\
\text { (UFFS) }\end{array}$ & $\begin{array}{l}\text { Criação, indiretamente, da Universidade Federal } \\
\text { do Pampa (UNIPAMPA) }\end{array}$ \\
\hline
\end{tabular}

(Continua) 


\begin{tabular}{|c|l|l|}
\hline \multirow{2}{*}{$\begin{array}{c}\text { Executores } \\
\text { das Ações }\end{array}$} & $\begin{array}{l}\text { Fórum da Mesorregião, com } \\
\text { participação das universidades do } \\
\text { norte do Estado, Conselhos Regionais } \\
\text { de Desenvolvimento (Coredes). } \\
\text { Municípios e participação tímida do } \\
\text { Governo do Estado. Fundações e } \\
\text { organizações não-governamentais, } \\
\text { como a Agência de Desenvolvimento } \\
\text { Regional do Sudoeste do Paraná, do } \\
\text { Instituto de Desenvolvimento Regional } \\
\text { SAGA, de Chapecó, e da Fundação Vale } \\
\text { do Rio Turvo para Desenvolvimento } \\
\text { Sustentável (FUNDATURVO/DS) }\end{array}$ & $\begin{array}{l}\text { Fórum da Mesorregião, com atuação dos Coredes } \\
\text { e universidades regionais. A execução das ações a } \\
\text { cargo dos municípios, da Embrapa e do próprio } \\
\text { Governo do Estado. }\end{array}$ \\
\hline
\end{tabular}

Fonte: Elaboração própria com base em: Portal Ministério da Integração Nacional, 2007; Rambo, Deves e Andrade (2008, p.162); Cargin, 2014.

No âmbito destas duas mesorregiões (figura 02), foram definidos como prioridades para o desenvolvimento regional os setores de gemas, joias, pescado, turismo, embutidos de suíno e derivados de leite para a Mesorregião GFM e, florestamento, fruticultura e sementes agroecológicas para a Mesorregião da Metade Sul (CARGIN, 2014). Destaca-se ainda que foi prevista e executada a organização do Fórum de Desenvolvimento Mesorregional em cada um dos recortes regionais ${ }^{7}$. Com estes fóruns, propunha-se um sistema de gestão, protagonizado pelos atores sociais, no intuito de fortalecer a densidade da rede de atores na região. A execução dos programas foi conduzida por agências de desenvolvimento, por outras instituições regionais e por acordos com municípios (FERREIRA, MOREIRA, 2007).

O estudo do caso da GFM mostra a importância da gestão local e da elaboração de um plano de desenvolvimento com base nas características e demandas regionais, atendendo assim aos objetivos da PNDR. A escolha desta Mesorregião é porque ela se sobrepõe geograficamente a uma porção territorial dos três estados da Região Sul do Brasil, articulando institucionalidades de forma regionalizada, em prol do desenvolvimento regional.

\section{Mesorregião da Grande Fronteira do Mercosul - estudo de caso da PNDR}

Ainda no ano de 1997 houve uma primeira iniciativa de organização regional no âmbito da GFM com o Plano da Bacia do Rio Uruguai. Como forma de inclusão no PPA, em

\footnotetext{
${ }^{7}$ Por exemplo, o portal da Mesorregião Grande Fronteira do Mercosul: http://www.mesomercosul.org.br/ 
1999 esta ação resultou na criação da Mesorregiões Diferenciadas e, portanto, na ampliação da PNDR. A institucionalização da GFM ocorreu no ano de 2002, com a criação do Fórum da Mesorregião e atualmente a GFM é composta por 396 municípios: 223 do Rio Grande do Sul, 131 catarinenses e 42 paranaenses.

No caso da Grande Fronteira do Mercosul, a primeira iniciativa no sentido de planejar o desenvolvimento, ocorreu ainda em 2001, com a elaboração da Carta da Mesorregião, a qual apontou como ações prioritárias (1) desenvolvimento da agricultura familiar; (2) desenvolvimento do turismo; (3) geração e transferência de tecnologia; (4) gestão e sustentabilidade ambiental para o desenvolvimento; (5) capacitação para projetos de desenvolvimento; e (6) acesso ao crédito (CARTA DA MESORREGIÃO GRANDE FRONTEIRA DO MERCOSUL, 2001). Adotando uma concepção de desenvolvimento como fenômeno complexo e multidimensional, o Plano aponta quatro dimensões que merecem atenção especial. São elas: econômica, ambiental, social, político-institucional. Nas subseções que seguem serão analisados aspectos do Plano, da Gestão do Promeso e da questão da divisão regional, bem como uma análise geral da PNDR na GFM.

\subsection{Quanto aos atores da Gestão do Promeso na GFM}

Com base nos resultados da pesquisa com dados secundários, quanto aos atores envolvidos na gestão do Programa, no Rio Grande do Sul, o processo foi sendo liderado pelo Fórum da Mesorregião, com forte participação das Universidades do norte do Estado, em conjunto com os Conselhos Regionais de Desenvolvimento (Coredes). Hoje o fórum conta oficialmente com 76 integrantes, sendo 26 do Rio Grande do Sul, 32 de Santa Catarina e 16 do Paraná.

Observou-se também o envolvimento dos municípios e participação tímida do Governo do Estado. Além disso, fundações e organizações não governamentais responsabilizaram-se pela execução dos projetos (ver quadro 2), como no caso da Agência de Desenvolvimento Regional do Sudoeste do Paraná, do Instituto de Desenvolvimento Regional SAGA, de Chapecó, e da Fundação Vale do Rio Turvo para Desenvolvimento Sustentável (FUNDATURVO/DS) (CARGNIN, 2014). 
Ainda de acordo com Cargnin (2014), as ações desenvolvidas no âmbito do Promeso, estão em consonância com o planejamento e as linhas estratégicas adotadas pela Mesorregião, vinculados aos conceitos de desenvolvimento endógeno, de acordo com os Arranjos Produtivos Locais priorizados no contexto da política nacional. A viabilização dos projetos conta com mobilização dos atores, sendo influenciada pelas universidades comunitárias, que são as responsáveis pela elaboração dos mesmos e pelos Coredes. Isto pode ser observado no comentário do Entrevistado 1:

"[...] a própria experiência dos Coredes, ela foi de certa forma também utilizada para o desenho da própria organização do Fórum da Mesorregião, tanto que no próprio Fórum dos Coredes, na reunião dos 28 Coredes, sempre tem (...) era comum né, os presidentes dos fóruns estarem presentes para discutir políticas, questões, enfim, de interesse comum né, das Mesos e dos Coredes". (Entrevista 1 - membro do Fórum da GFM/RS, 2016 - grifo nosso).

No Estado do Paraná, há de se destacar a atuação da Agência de Desenvolvimento Regional do Sudoeste do Paraná (Agência). A Agência caracteriza-se como uma Organização da Sociedade Civil de Interesse Pública (OSCIP) e foi criada por iniciativa da Associação de Municípios do Sudoeste do Paraná (AMSOP), no ano de 2000. Desse modo, verifica-se uma consciência em escala local/regional sobre a importância da integração das diversas institucionalidades mobilizadas - Corede, Fórum, Colegiado - em torno do desenvolvimento regional, muito embora, seja aquém do que desejam os atores que buscam por tal integração.

Os entrevistados destacaram também a questão da gestão social promovida pelo Promeso e a possibilidade dos atores locais/regionais poderem definir as prioridades a serem atendidas pela política:

\footnotetext{
"Então, eu diria que para integração produtiva, inclusão produtiva, a política era excelente. E ela era realmente, é um grande esforço de horizontalização da ação do governo. Hoje é muito vertical né. E o Estado brasileiro é extremamente vertical, $e$ aí, a PNDR, ela fez esse esforço de dialogar com os territórios, suas necessidades, seu jeito do povo né, suas características né. Então, era um bom desenho, só que não avançou" (Entrevista 2 - membro do Fórum da GFM/PR, 2016 - grifo nosso).
} 
Cabe ressaltar um ponto interessante elencado em pelo menos duas entrevistas no que se refere às emendas parlamentares, corroborando o que aponta a Câmara de Políticas de Desenvolvimento Regional (CPDR) que coordenou o processo da Conferência Nacional de Desenvolvimento Regional (CNDR) e a elaboração da PNDR II. Segundo o relatório da CNDR, um dos limitantes da PNDR foi o pouco recurso disponível e a elevada participação de emendas parlamentares. Entre 2004 e 2010 esses programas aplicaram R\$ 2,8 bilhões em todo o país, menos de $0,5 \%$ do que foi desembolsado pelos Fundos Constitucionais no mesmo período. As emendas, de modo geral, acabam descaracterizando o processo de gestão social e governança que as próprias políticas públicas propõem:

"[...] boa parte dos recursos, que a própria Meso utilizou nesse período vieram de emendas parlamentares. Só que pra mim as emendas são, digamos assim, um câncer que deveria ser extirpado, né, mas aí, assim, você acaba tendo que se submeter, a tentar e buscar junto com os deputados algum recurso né... Hã... mas não é isso né, que deveria ser". (Entrevista 1 - membro do Fórum da GFM/RS, 2016 - grifo nosso).

"[...] um elemento que foi um desastre da Constituição de 88, a tal da figura da emenda parlamentar (...) Esse foi um elemento, que aí você criou um poder dentro do poder (...)Então, hoje os mandatos são grandes cerceadores e grande dificultadores para implementar a política na horizontalidade. Isso é uma constatação nossa". (Entrevista 2 - membro do Fórum da GFM/PR, 2016 - grifo nosso).

Assim, podemos inferir que, por meio do Fórum e da elaboração do Plano foi possível combinar políticas públicas com articulação dos recursos locais para promover o desenvolvimento regional, tal como é expresso nos objetivos da PNDR. No entanto, há que se observar que os recursos para os projetos que são desenvolvidos na GFM são provenientes de Emendas Parlamentares; cerca de 2/3 deste valor correspondeu a recursos dessas emendas, que apresentam limitada vinculação com os objetivos dos programas e grande pulverização em pequenos projetos, cujo valor modal girou em torno de $\mathrm{R} \$ 100$ mil. Ou seja, mesmo com o baixo valor dos recursos, nem sempre esses correspondem às necessidades demandas pelo Plano elaborado com base na gestão social, mas sim por um aspecto político-partidário. 


\subsection{Quando à abrangência da Mesorregião}

Sobre a escala da Mesorregião, diferentes pesquisas e mesmo documentos oficiais apontam inadequações na composição destes recortes, encontrando resistência de Estados e Municípios. Isso porque os Estados mostraram-se críticos ao conteúdo federativo da PNDR, principalmente acerca do desenho das mesorregiões tipificadas pela política, já que Estados e Municípios não teriam sido consultados para tal divisão regional. Ainda, diversos entes municipais inseridos nas mesorregiões declararam-se alheios à lógica do enquadramento territorial (BRASIL, 2012).

O isolamento federativo da PNDR fez com que muitos Estados e Municípios não reconhecessem a tipologia da PNDR. No entanto, de forma divergente aos relatórios oficiais de avaliação da PNDR I, os entrevistados locais mostraram-se favoráveis à divisão escalar da PNDR, destacando a experiência propiciada pelos fóruns das mesorregiões, bem como a possibilidade de cooperação entre os estados. Isso pode ser comprovado pelos relatos que seguem.

\footnotetext{
"Eu acredito que sim, porque aí vem toda essa discussão do desenvolvimento, essa questão do multidimensionalidade e multisetorialidade. Então, esta escala de mesorregião, ela é uma escala importante e necessária, no meu entendimento. E aí quando entrou uma discussão, dentro do próprio Ministério da Integração, de tentar substituir essas políticas das mesorregiões diferenciadas pela ótica do desenvolvimento territorial, mais microrregional, dos territórios rurais ou da cidadania, para mim foi um equívoco, porque são escalas diferentes, são dinâmicas diferentes, né. Elas têm que estar integradas, tem que até, digamos assim, trabalhar junto né, mas substituir uma pela outra, eu acho que é um equívoco [...] As mesorregiões dá para se dizer que tem esse elemento territorial muito claro, né. Foi uma construção a partir, digamos assim, da identidade construída pelas regiões. [...]: E aí, vamos dizer assim, o fato de "ah, são 397 municípios, é mais que alguns estados e tal" não me parece que seja um problema" (Entrevista 1 - membro do Fórum da GFM/RS, 2016 - grifo nosso).

"[...] o esforço sempre do nosso Fórum foi combater o federalismo competitivo dos três estados. Nós idealizávamos né, um federalismo cooperativo. [...] nós evitávamos de fazer debates das porções estaduais porque nós criávamos, aprofundávamos essa questão do competitivoll (Entrevista 2 - membro do Fórum da GFM/PR, 2016 - grifo nosso).

"[...] acabou sendo para nós uma experiência muito importante. [...] E era uma escala adequada desde que a política de governo reconhecesse profundamente isso, certo? Porque queira ou não queira tem que ter uma estrutura programática, orçamentária de sustentação do processo. A prática mesorregional ela foi muito rica, (...) espaço político de discussão, liderança, organizações, pessoas, de uma porção que nem o Rio Grande do Sul, Santa Catarina, Paraná, enriquecia muito. Foi sempre muito enriquecedor essa troca de experiência né. Então, eu diria que sim (Entrevista 2 - membro do Fórum da GFM/PR, 2016).
} 
Assim, consideramos que o recorte mesorregional teve um papel importante na promoção do desenvolvimento, sobretudo pela integração de uma diversidade de atores dos três estados. No entanto, é um recorte que se viabiliza enquanto houver recursos aportando o processo. Um dos entrevistados do Fórum do GFM/Paraná apontou que, atualmente diante de uma proposta da PNDR II, a divisão da GFM seria relativamente grande e que a mesma poderia ser repensada diante de uma política territorial e sobre a divisão dos recursos orçamentários para execução dos projetos.

[...] é legal a experiência de pessoas, mas no operacional depois, de implementação do processo é bem mais complexo né. Gestão, etc. Acompanhamento... Hoje, por exemplo, a gente percebe já que tem muito mais uma conexão, uma vivência maior entre paranaenses e catarinenses e não gaúchos. O Rio Uruguai, na verdade, é um bom divisor não só das águas ali, mas de cultura. A gente percebe que o Rio Grande do Sul, hoje, [...] o norte, noroeste, se volta muito para a capital gaúcha né. E ali têm os Coredes, têm os conselhos estaduais... (Entrevista 2 - membro do Fórum da GFM/PR, 2016 - grifo nosso).

4.3 Quanto aos objetivos e aspectos gerais do Promeso - PNDR

Quanto ao Promeso ter atingido seus objetivos, sobretudo no que diz respeito a compreender as diferenças de cada região, potencialidades e limites, para então buscar alternativas adequadas à realidade dessas regiões, o entrevistado 1 do Fórum da GFM/RS menciona ser difícil mensurar impactos reais de políticas públicas na promoção de melhores condições sociais e econômicas para população. Não raro, em curto e médio prazo, os índices aos quais se tem acesso - IDH e IDESE - não sofrem influencia de determinadas políticas, em parte por refletirem ações pontuais e pela escassez de recursos dispensados às políticas, ou por estes projetos carecerem de metodologias que permitam medir os avanços no modo de vida e produção dessas regiões.

Outro ponto negativo da política é a dificuldade no levantamento e obtenção de dados sobre os recursos de fato investidos ao longo dos anos na Mesorregião GFM, conforme Rambo, Deves e Andrade (2008). As pesquisas de Cargnin (2014b) e o Relatório Anual de Acompanhamento do Plano Plurianual 2000-2003 apontaram cinco ações para a GFM, todas realizadas em sua totalidade, sendo que $87 \%$ dos recursos, foram empregados na implementação do planejamento regional. 
Um ponto positivo do Promeso pode ser visualizado pelo biograma do gráfico 1, uma vez que este reflete a percepção dos oito entrevistados da GFM. Questionados sobre os objetivos específicos, observamos que o mais bem avaliado foi a promoção da organização social, recebendo nota 3,4 numa escala que variava de 0 (não alcançou o objetivo) a 5 (alcançou totalmente o objetivo), seguido da Promoção do Desenvolvimento Endógeno, com nota 2,67. Essa avaliação ressalta a importância dos Fóruns e dos próprios mecanismos de gestão social executados pelo Promeso na GFM.

\section{Gráfico 1 - Percepção dos entrevistados sobre os objetivos específicos do Promeso}

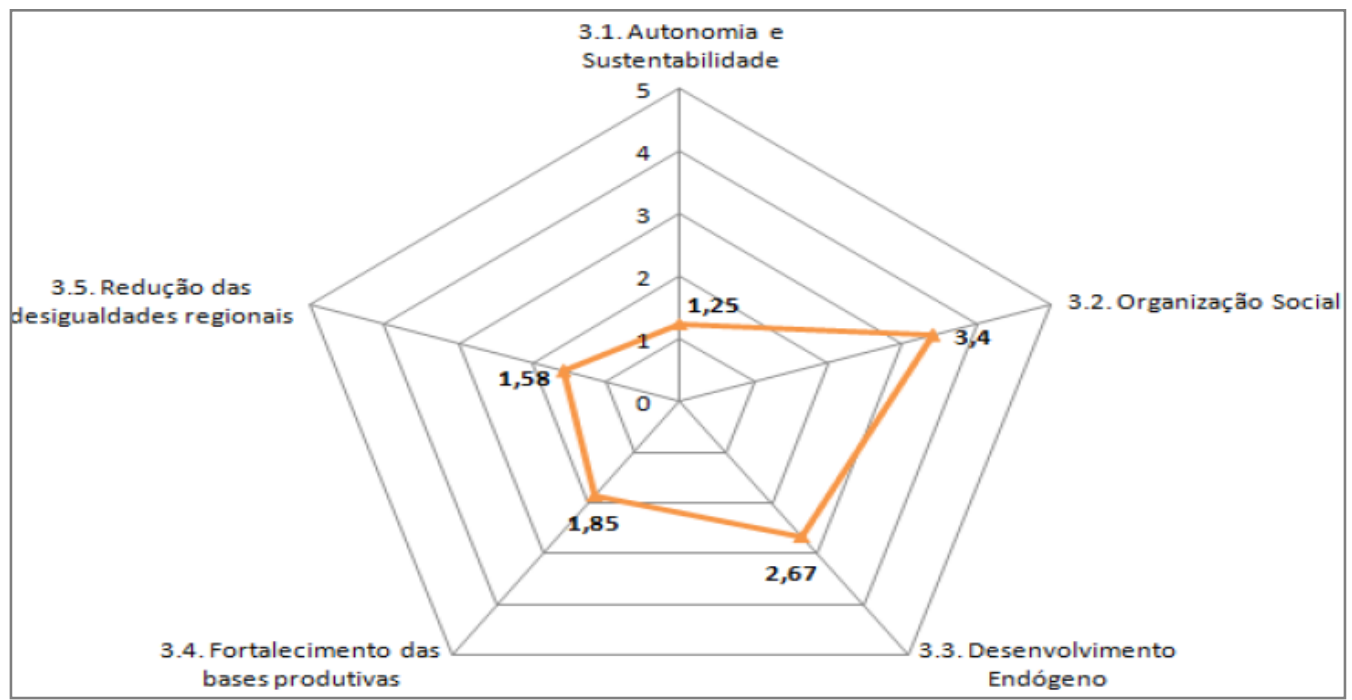

Fonte: Trabalho de campo. Organização própria.

Destaca-se que na avaliação dos atores envolvidos, os projetos para a promoção do desenvolvimento regional mostram que independentemente da escala de execução, o alcance dos objetivos desses mecanismos está relacionado ao poder dos atores sobre o território. Com base em Brandão (2008), podemos dizer que a ação pública deve chamar para si a tarefa de organizar e coordenar o sistema socioeconômico e decisório regional, opor e vencer resistências do atraso estrutural e anticidadão, ativar e mobilizar instrumentos, normas e convenções que se localizam em variados âmbitos, níveis de ação governamentais.

Outra externalidade positiva do Promeso, no Sudoeste do Paraná, refere-se à elaboração do Plano de Desenvolvimento Regional Integrado (PDRI) de 2015. Conforme 
mencionado pelo membro do Fórum da GFM/PR, o PDRI hoje está muito próximo ao plano da PNDR I, tendo então como objetivo estimular o desenvolvimento econômico, social, ambiental e institucional dos municípios do Sudoeste, de modo a atuar sobre os problemas e/ou oportunidades regionais específicas (PDRI, 2015).

Ao analisarmos o Plano de Ação da Mesorregião, em seu eixo de crescimento econômico, é possível verificar que vários programas fazem menção direta com o espaço rural, tais como: agricultura sustentável com base na agricultura familiar diversificada e enfoque de cadeias produtivas; agregação de valor aos produtos de atividade primária; produção agroecológica. Conforme Cargnin (2014), ainda na primeira fase do Promeso, foram apoiadas agroindústrias nos três estados do Sul e, na segunda etapa, a meta foi ampliada para 150 agroindústrias, sendo o fomento às agroindústrias, uma das ações mais executadas pelo Promeso.

Destaca-se que a preexistência da PNDR II, com uma proposta de tipologia de Regiões Programa (RPs) e Sub-Regiões de Planejamento (SRPs) em diferentes escalas, que, em função de suas peculiaridades e/ou identidades, devem ser objeto de programas de intervenção e planejamentos específicos. Algumas destas regiões serão definidas de partida, em especial aquelas que já são objeto da PNDR I. Outras, podendo ser definitivas ou temporárias, serão estabelecidas de comum acordo com os entes federados e atores da sociedade civil envolvidos (BRASIL, 2012).

Ressalta-se que o texto da PNDR II está em tramitação no Senado Federal desde junho de 2015. Em março de 2018 foi publicado pelo Ministério da Integração Nacional o Decreto no 8.980, que estabelece como proposta para a PNDR II as Rotas de Integração Nacional. Pelo texto publicado, as "ROTAS, como estratégia de desenvolvimento regional e inclusão produtiva no âmbito do Programa 2029 - Desenvolvimento Regional e Territorial (PPA 2016-2019), tem objetivo de promover a estruturação de atividades produtivas, arranjos produtivos e rotas de integração para o desenvolvimento regional e territorial” ${ }^{8}$.

\footnotetext{
${ }^{8}$ Ver Decreto em:

<http://pesquisa.in.gov.br/imprensa/jsp/visualiza/index.jsp?data=01/03/2018\&jornal=515\&pagina=40>. 


\section{Considerações finais}

Esta breve explanação acerca da Política Nacional do Desenvolvimento Regional e a análise do caso do Promeso na Grande Fronteira do Mersocul demonstra que as estratégias de desenvolvimento provenientes desta política proporcionaram repercussões favoráveis à promoção do desenvolvimento, embora haja muito a avançar. Cabe destacar que a PNDR passou a abarcar regiões e atores que anteriormente não eram foco das políticas, que estavam bastante restritas à porção litorânea e regiões metropolitanas brasileiras, os quais passaram então a dialogar e discutir suas demandas, suas necessidades e interesses, valorizando o capital social local.

Verificamos avaliações positivas dos atores no que se refere à contribuição da política para o desenvolvimento através dos projetos elencados como prioritários. Segundo os próprios entrevistados, isso se deve em grande parte, a possibilidade de maior participação destes atores nas discussões atinentes ao seu desenvolvimento. Tal participação é possibilitada pelos mecanismos de governança, no caso, o Fórum da Mesorregião da GFM, um exemplo de que as transformações que promovem o desenvolvimento resultam de complexas interações sociais, nas quais o foco principal é a ampliação do horizonte de possibilidades da sociedade.

Acredita-se que as políticas de desenvolvimento ainda carecem ampliar seu agir sobre a totalidade do tecido socioprodutivo, pensar o conjunto como um todo sistêmico, promovendo ações concertadas no espaço geográfico, buscando reduzir disparidades interregionais, combatendo o fosso entre as regiões e ampliando a autodeterminação nas comunidades, como aponta Brandão (2003). Isso permite retomar a proposição de Sergio Boiser: os processos de desenvolvimento regional promovidos pela PNDR/Promeso, apesar dos avanços, ainda representam uma caixa-preta, na medida em que se mostra necessário avançar na articulação dos seis elementos apontados pelo autor.

Por fim, é necessário que o Plano Mesorregional seja um instrumento de planejamento de curto, médio e longos prazos, construído e assumido regionalmente, para que não se limite a um instrumento legal de determinada política pública, mas sim um instrumento político de mobilização, reivindicação e norteador das dinâmicas territoriais 
regionais. Ainda, é preciso ampliar a participação dos atores locais/regionais, promover a articulação entre as diferentes escalas de gestão do desenvolvimento, de modo que as políticas públicas implementadas sobre um mesmo território se complementem, considerando as dinâmicas do entorno, seja regional, estadual, nacional e internacional.

\section{Referências}

BARQUERO, A. V. Desenvolvimento Endógeno em Tempos de Globalização. Porto Alegre: Fundação de Economia e Estatística, 2001.

BOISIER, S. Desarrollo (Local): ?De que estamos hablando? In: BECKER, D. F.; BANDEIRA, P. S. (orgs.) Determinantes e desafios contemporâneos. Santa Cruz do Sul: Edunisc, 2000, p.151186.

BOISIER, S. et al. Sociedade civil, actores socialis y desarrollo regional. Santiago do Chile: Ilpes/Cepal, 1995.

BRANDÃO, Carlos. Desenvolvimento, territórios e escalas espaciais: levar na devida conta as contribuições da economia política e da geografia crítica para construir a abordagem interdisciplinar. In RIBEIRO, Maria Teresa Franco; MILANI, Carlos R. S. (orgs).

Compreendendo a complexidade sócio espacial contemporânea: o território como categoria de diálogo interdisciplinar. Salvador, Editora da UFBA, 2008.

BRASIL. Ministério do Planejamento, Orçamento e Gestão. Secretaria de Planejamento e Investimentos Estratégicos e Centro de Gestão e Estudos Estratégicos. Estudo da dimensão territorial do PPA: marco inicial. Secretaria de Planejamento e Investimentos Estratégicos e Centro de Gestão e Estudos Estratégicos. - Brasília: SPI/MP, 2006.

Ministério da Integração Nacional. Secretaria de Programas Regionais. Programa de Promoção da Sustentabilidade de Espaços Sub-regionais (Promeso), IICA, Brasília, 2009.

BRASIL, Secretaria de Desenvolvimento Regional. I Conferência Nacional de Desenvolvimento Regional. Documento de referência, 2012. Disponível em: http://mi.gov.br/c/document_library/get_file?uuid=54bce099-503a-4076-8613d90dd6107c79\&groupld=10157 Acessos em jan/2018.

. Ministério da Integração. PNDR I - Política Nacional de Desenvolvimento Regional. Disponível em: http://www.mi.gov.br/politica-nacional-de-desenvolvimentoregional-pndr Acessado em jul 2015.

CARGNIN, A. P. Política Nacional de Desenvolvimento Regional e Repercussões no Rio Grande do Sul. Mercator, Fortaleza, v. 13, n. 1, p. 19-35, jan./abr. 2014. 
Políticas de Desenvolvimento Regional no Rio Grande do Sul: vestígios, marcas e repercussões territoriais. Brasília: Ministério da Integração nacional, 2014b.

CARTA DA MESORREGIÃO GRANDE FRONTEIRA DO MERCOSUL. Disponível em: www.mesomercosul.org.br/imgs/carta.doc. Acesso em: ago/2016.

DUPAS, G. O mito do progresso: ou progresso como ideologia. São Paulo: UNESP, 2006.

FERNÁNDEZ, V. R.; AMIN, A.; VIGIL, J. I. (comp.). Repensando el desarrollo regional: contribuiciones globales para una estratégia latino-americana. Buenos Aires: Editorial Miño y Dávila, 2008, p. 101-120.

FERREIRA, H. V. da C.; MOREIRA, M. Programas de mesorregiões diferenciadas: subsídios à discussão sobre a institucionalização dos programas regionais no contexto da PNDR. In: DINIZ, Clélio C., (Org.). Políticas de Desenvolvimento Regional: desafios e perspectivas à luz das experiências da União Europeia e do Brasil. Brasília, Editora da Universidade, 2007, p.353-379.

FURTADO, C. Formação Econômica do Brasil. 32. ed. São Paulo: Companhia Editora Nacional, 2003.

GALVÃO, Antonio C. Prefácio. In: Para Pensar uma Política de Ordenamento Territorial. Brasília: IICA/Ministério da Integração Nacional, 2005.

IPEA (Instituto de Pesquisa Econômica Aplicada). Brasil em desenvolvimento 2011: Estado, planejamento e políticas públicas. Brasília: IPEA, 2012.

MENDES, C. C.; MATTEO, M. Formação e evolução do planejamento regional no Brasil. In: CRUZ, Bruno de Oliveira et al. Economia regional e urbana: teorias e métodos com ênfase no Brasil. Brasília : Ipea, 2011,.261-280.

MONASTERIO, L.; CAVALCANTE, L. R. Fundamentos do pensamento econômico regional. In CRUZ, Bruno de Oliveira et al. Economia Regional e urbana: teorias e métodos com ênfase no Brasil. Brasília: IPEA, 2011, p.43-77.

PDRI, Plano de Desenvolvimento Regional Integrado. Plano Tático PDRI - uma jornada pelo desenvolvimento, Fracisco Beltrão: 2015.

RAFFESTIN, Claude. Por uma geografia do poder. São Paulo: Ática, 1993.

RAMBO, A. G.; DEVES, O. D.; MIGUEL, L. A. Sistemas agrários, políticas públicas e desenvolvimento territorial local/regional: considerações acerca da porção oeste da mesorregião Grande Fronteira do Mercosul - Brasil, Revista Pampa, 2008.

RUCKERT, Aldomar A. Reforma do estado, reestruturações territoriais, desenvolvimento e novas territorialidades. Geousp, São Paulo, n. 17. p. 79-94, 2005. Disponível em: www.geografia.fflch.usp.br/publicacoes/Geousp/Geousp17/index.html 